Article

\title{
Effects of Superheated Steam Treatment on the Allergenicity and Structure of Chicken Egg Ovomucoid
}

\author{
Ping-Wei Wen ${ }^{1,2,3}$, Zong-Cai Tu ${ }^{1,2,3, *}$, Yue-Ming $\mathrm{Hu}^{3}$ and Hui Wang ${ }^{3}$ \\ 1 National R\&D Branch Center for Conventional Freshwater Fish Processing, College of Chemistry and \\ Chemical Engineering, Jiangxi Normal University, Nanchang 330022, China; wenpingwei@ncu.edu.cn \\ 2 Engineering Research Center of Freshwater Fish High-Value Utilization of Jiangxi Province, \\ Jiangxi Normal University, Nanchang 330022, China \\ 3 State Key Laboratory of Food Science and Technology, Nanchang University, Nanchang 330047, China; \\ huyueming@ncu.edu.cn (Y.-M.H.); wanghui00072@ncu.edu.cn (H.W.) \\ * Correspondence: tuzc_mail@aliyun.com; Tel.: +86-791-8812-1868; Fax: +86-791-8830-5938
}

check for updates

Citation: Wen, P.-W.; Tu, Z.-C.; Hu, Y.-M.; Wang, H. Effects of Superheated Steam Treatment on the Allergenicity and Structure of Chicken Egg Ovomucoid. Foods 2022, 11, 238. https://doi.org/10.3390/ foods 11020238

Academic Editor: Jan Mei Soon

Received: 14 December 2021

Accepted: 12 January 2022

Published: 17 January 2022

Publisher's Note: MDPI stays neutral with regard to jurisdictional claims in published maps and institutional affiliations.

Copyright: (C) 2022 by the authors. Licensee MDPI, Basel, Switzerland. This article is an open access article distributed under the terms and conditions of the Creative Commons Attribution (CC BY) license (https:// creativecommons.org/licenses/by/ $4.0 /)$.

\begin{abstract}
The aim of this study was to explore the effects of an emerging and efficient heating technology, superheated steam (SS), on the allergenicity and molecular structure of ovomucoid (OVM). OVM was treated with $120-200{ }^{\circ} \mathrm{C}$ of SS for 2 to $10 \mathrm{~min}$. The allergenicity (IgG/IgE binding abilities and cell degranulation assay) and molecular structure (main functional groups and amino acids modification) changes were investigated. The IgG-binding ability of OVM decreased and the releases of $\beta$-hex and TNF- $\gamma$ were inhibited after SS treatment, indicating that the protein allergenicity was reduced. Significant increases in oxidation degree, free SH content and surface hydrophobicity were observed in SS-treated OVM. The protein dimer and trimer appeared after SS treatment. Meanwhile, obvious changes occurred in the primary structure. Specifically, serine can be readily modified by obtaining functional groups from other modification sites during SS treatment. Moreover, the natural OVM structure which showed resistance to trypsin digestion was disrupted, leading to increased protein digestibility. In conclusion, SS-induced OVM aggregation, functional groups and amino acids modifications as well as protein structure alteration led to reduced allergenicity and increased digestibility.
\end{abstract}

Keywords: ovomucoid; superheated steam; modification; allergenicity; mass spectrometry

\section{Introduction}

Egg is the main daily protein source for human beings, and also one of the major ingredients in the food industry [1]. However, egg allergy is common among infants and young children, and a high proportion of patients suffer the egg allergy throughout their lives [2]. Egg allergens are concentrated in egg white proteins, including ovomucoid (OVM), ovalbumin, ovotransferrin and lysozyme, among which, OVM is considered as the predominant component of egg allergens [3]. It is urgent to explore an effective and safe technology to reduce the allergenicity of eggs.

Previous studies have shown that heating, high pressure, glycation and hydrolysis can decrease the protein allergenicity $[1,4,5]$. Heat processing includes dry-heating and heatmoisture treatments. There are two drawbacks of traditional heating approaches for protein modification. One is that they often consume long periods of time, and the other is that the protein solubility is always decreased. Moreover, the traditional heating treatments are not drastic enough to alter specific sequences and conformation of allergenic epitopes and could not significantly decrease the protein allergenicity. Among the egg protein components, OVM showed the strongest heat resistance, and even $100{ }^{\circ} \mathrm{C}$ of heating for 60 min could not lead to the denaturation of OVM [6]. It is necessary to explore new high temperature heating methods to efficiently alter the OVM structure and modify/disrupt/bury the allergen epitopes of protein. 
Superheated steam (SS) treatment is an emerging heating method and has attracted more and more attention for its advantages, including higher heat transfer efficiency, lowoxygen and pollution-free environment as well as good quality of processed products [7]. During SS processing, a large amount of heat is transferred to food when steam condenses on food surfaces, which rapidly increases the food temperature. The efficiency of SS has recently been demonstrated in several different food processing fields by dramatically reducing the processing time from days and h to min or even s [8]. SS-treated vegetables, grains, meats, etc. showed better functional and textural properties as well as higher nutritional qualities than those treated by conventional heating methods $[9,10]$. SS was also proven to improve the physicochemical and nutritional properties of biological macromolecules, including starch and protein, etc. [11,12]. Hu, Wang, and Li [7] reported that SS treatment could promote the covalent and non-covalent interactions as well as alter the conformation of wheat gluten. However, to date, the application of SS on the modification of natural structure and nutrition of food components is still lacking. Particularly, the effects of SS processing on allergenicity and the molecular structure of egg proteins have rarely been reported.

The objective of the study is to find a new, easily operated, efficient and safe technology to reduce the allergenicity of proteins. Our preliminary experiments showed that SS is an effective approach to modifying egg proteins and reducing the allergenicity. It is necessary to perform experiments to prove those effects.

Previous research demonstrated that egg proteins allergies are mainly originated from immunoglobulin G (IgG) and immunoglobulin E (IgE)-mediated rapid allergic reaction. In addition, macrophages are also important effector cells that mediate immune response [2]. The mediators released from basophils may be responsible for the occurrence of Type I allergic reactions. Therefore, in this study, the allergenicity changes of SS-treated OVM were revealed by the following experiments: (1) IgG and IgE binding abilities analysis through enzyme-linked immunosorbent assay (ELISA) with rabbit polyclonal antibodies and sera from patients allergic to egg, respectively. (2) Histamine, $\beta$-hexosaminidase ( $\beta$-hex), TNF- $\gamma$, and interleukin-6 (IL-6) releases determination using a basophil cell line (KU812) model.

The protein allergenicity changes are reported related to the alteration in molecular structure in terms of primary structure, main functional groups and degree of protein aggregation [1-5]. Therefore, in this study, the changes in the surface hydrophobicity, free sulfhydryl (SH) content, molecular weight and amino acids modification of OVM were investigated to preliminary interpret the mechanism of SS-induced protein allergenicity alteration.

\section{Materials and Methods}

\subsection{Chemicals and Materials}

OVM, D-glucose, goat antirabbit IgG-HRP conjugate, goat antihuman IgE-HRP conjugate and trypsin were purchased from Sigma-Aldrich (St. Louis, MO, USA). Dithiothreitol (DTT) was purchased from Thermo Fisher Scientific Inc. (Waltham, MA, USA). The KU812 cells were obtained from iCell Bioscience (Shanghai, China). All other reagents used were of analytical reagent grade. Ultrapure water from a water purification system (Millipore; Billerica, MA, USA) was used throughout this study.

The sera of six egg white allergy (EWA) patients were purchased from Plasma Lab International. The specific IgE levels of six groups of sera were 10.8, 26.3, 24.9, 13.5, 16.5 and $12.8 \mathrm{kU} / \mathrm{L}$. The six groups of sera were mixed and served as human anti-OVM IgE serum and stored at $-80{ }^{\circ} \mathrm{C}$ until used.

Preparation of rabbit anti-OVM IgG serum: Male Japanese rabbits (100 days) (permission number, SCXK (Gan) 2014-0005) were purchased from Longping (Nanchang, China). After acclimatizing in a breeding room for 10 days, the rabbits were intravenously injected with $1 \mathrm{~mL}$ OVM $(0.8 \mathrm{mg} / \mathrm{mL})$ emulsified with the Freund's complete adjuvant $(v / v, 1: 1)$. The booster immunization was taken after one, two and three weeks at a dose of $0.4 \mathrm{~mL}$, respectively. After the rabbits were anesthetized, the rabbit anti-OVM IgG plasma was 
collected. After being centrifuged at $4{ }^{\circ} \mathrm{C}$, the rabbit anti-OVM IgG serum was separated and stored at $-80^{\circ} \mathrm{C}$ until used.

\subsection{SS Processing}

An SS processing system developed by the Food Engineering Center of Nanchang University was used in this study. The schematic diagram was detailed and shown in the report of Wu et al. [13]. A total of $200 \mathrm{mg}$ OVM powder was spread in a culture dish. When the temperature in the SS chamber was kept stable, the culture dish was inserted into the processing chamber. Processing of OVM samples was conducted at atmospheric pressure. The flow velocity of SS was $1.0 \mathrm{~m} / \mathrm{s}$. The treatment temperatures were 120, 140, 160,180 and $200{ }^{\circ} \mathrm{C}$. The processing times were 2, 4, 6, 8 and $10 \mathrm{~min}$. After being treated for the set time, the OVM sample was taken out of the processing chamber and then cooled in an ice bath. Native OVM was served as the control. All the samples were stored at $4{ }^{\circ} \mathrm{C}$ until used.

\subsection{IgG and IgE-Binding Abilities}

The IgG and IgE-binding abilities of the OVM samples were estimated with indirect competitive ELISA according to our previous report [14]. Rabbit anti-OVM IgG serum and human anti-OVM IgE serum were used to determine IgG-binding ability and IgE-binding ability, respectively. A 96-well microplate was coated with $2 \mu \mathrm{g} / \mathrm{mL}$ of native OVM at $37^{\circ} \mathrm{C}$ for $1 \mathrm{~h}$. Then residual free binding sites were blocked with $1 \%$ fish gelatin solution and incubated at $37^{\circ} \mathrm{C}$ for $1 \mathrm{~h}$. Next, the diluted samples and the serum of rabbit or EWA patients were injected into the microplate and incubated at $37^{\circ} \mathrm{C}$ for $1 \mathrm{~h}$. After removing the solutions, the microplate was washed with PBST five times. Goat antirabbit IgG-HRP conjugate $(100 \mu \mathrm{L}$, diluted at 1:2500) or goat antihuman IgE-HRP conjugate $(100 \mu \mathrm{L}$, diluted at 1:700) was injected and then incubated at $37^{\circ} \mathrm{C}$ for $1 \mathrm{~h}$. Finally, tetramethylbenzidine (TMB, $100 \mu \mathrm{L}$ ) was immediately added to each well and purged with sulfuric acid. The absorbance was measured at $450 \mathrm{~nm}$ and the decline rate was calculated using the equation:

$$
\text { Inhibition }(\%)=\left(1-\mathrm{B} / \mathrm{B}_{0}\right) \times 100 \%
$$

where $\mathrm{B}_{0}$ and $\mathrm{B}$ indicate the optical density $(\mathrm{OD})$ value of a well with the control and SS-treated OVM, respectively.

\subsection{Human Peripheral Blood Basophilic Leukemia Cells (KU812 Cells) Culture and Degranulation Assay}

The basophil histamine release test was carried out according to the method of Wang et al. [15]. KU812 cells were cultured in RPMI-1640 medium with $20 \%$ fetal bovine serum (FBS) and $105 \mathrm{U} / \mathrm{L}$ penicillin/streptomycin for $24 \mathrm{~h}$. A total of $5 \times 10^{5}$ cells was in each well. The culture condition was $37^{\circ} \mathrm{C}$ with $\mathrm{CO}_{2}(5 \%)$. The cells were then activated with human anti-OVM IgE serum for $24 \mathrm{~h}$, and followed by, stimulated by $50 \mu \mathrm{g} /$ well of samples for $4 \mathrm{~h}$. Cells treated with PBS buffer were served as the negative control. The release of $\beta$-hex, TNF- $\gamma$, histamine and IL- 6 were analyzed by ELISA kits, following the manufacturer's instructions [16,17].

\subsection{Determination of Protein Carbonyl Content}

The carbonyl content of the OVM samples was determined according to the method of Zhang et al. [18] with slight modifications. The measurements were performed by monitoring the reaction between 2,4-dinitrophenylhydrazine (DNPH) and the carbonyl group of the protein. An amount of $0.2 \mathrm{~mL}$ of OVM $(4 \mathrm{mg} / \mathrm{mL})$ was mixed with $0.4 \mathrm{~mL}$ of DNPH $(10 \mathrm{mmol} / \mathrm{L}$, in $2 \mathrm{~mol} / \mathrm{L} \mathrm{HCl})$ and the mixture was incubated at $37^{\circ} \mathrm{C}$ in the dark for $1 \mathrm{~h}$. Followed by $0.5 \mathrm{~mL}$ of $20 \%$ trichloroacetic acid was added and the solution was incubated for $5 \mathrm{~min}$. The sample was then centrifuged at 12,000 rpm and $4{ }^{\circ} \mathrm{C}$ for $15 \mathrm{~min}$. The supernatant was removed, and the precipitate was retained. The sediment was washed using $1 \mathrm{~mL}$ of ethyl acetate/ethanol (1:1) mixture and then centrifuged with the 
method described above three times. The obtained protein was incubated with $1 \mathrm{~mL}$ of guanidine hydrochloride solution $(6 \mathrm{~mol} / \mathrm{L})$, and the solution was centrifuged to remove precipitation. Absorption at $370 \mathrm{~nm}$ was determined using a U-2910 ultraviolet-visible spectrophotometer. The blank was applied with the same method except using $\mathrm{HCl}$ $(2 \mathrm{~mol} / \mathrm{L})$ instead of DNPH. The carbonyl content was calculated with a molar extinction coefficient of $22,000 \mathrm{~mol}^{-1} \cdot \mathrm{cm}^{-1}$, and the result was expressed as nmol/mg protein.

\subsection{Determination of Surface Hydrophobicity}

The surface hydrophobicity of the OVM samples was determined by an 8-aniline-1naphthalene sulfonic acid (ANS) fluorescence probe method [19]. The samples were diluted to $1,0.5$ and $0.25 \mathrm{mg} / \mathrm{mL}$, and the fluorescence intensities were determined by mixing $4 \mathrm{~mL}$ of each sample with $20 \mu \mathrm{L}$ of ANS solution $(8 \mathrm{mmol} / \mathrm{L})$. The measurement conditions were as follows: excitation wavelength of $390 \mathrm{~nm}$; scanning emission wavelength range of $400-600 \mathrm{~nm}$; slit width of $5 \mathrm{~nm}$. A linear regression equation was prepared according to the fluorescence intensities of the samples at each concentration for curve fitting. The obtained slope was the surface hydrophobicity of the samples.

\subsection{Determination of FREE SH Content}

The free SH content of OVM samples was determined according to the method of Ellman [20] with slight modifications. Ellman's reagent was prepared according to the following procedure: first, $0.369 \mathrm{~g}$ of DTNB was dissolved in $50 \mathrm{mmol} / \mathrm{L} \mathrm{Na}_{2} \mathrm{HPO}_{4}(\mathrm{pH} 7.0)$; then, the volume was adjusted to $100 \mathrm{~mL}$; the reagent was stored at $4{ }^{\circ} \mathrm{C}$ in the dark. The protein samples were diluted to $2 \mathrm{mg} / \mathrm{mL}$ with $0.1 \mathrm{~mol} / \mathrm{L}$ phosphate buffer $(\mathrm{pH} 8.0$ ) containing $0.086 \mathrm{~mol} / \mathrm{L}$ Tris- $\mathrm{HCl}, 0.09 \mathrm{~mol} / \mathrm{L} \mathrm{Gly,} 4 \mathrm{mmol} / \mathrm{L}$ EDTA and $8 \mathrm{~mol} / \mathrm{L}$ urea. The diluted protein solution $(1 \mathrm{~mL})$ was mixed with buffer solution $(8 \mathrm{~mL})$, and centrifuged at $8000 \mathrm{r} / \mathrm{min}$ for $20 \mathrm{~min}$. Following this, $4.5 \mathrm{~mL}$ of supernatant was added to $0.5 \mathrm{~mL}$ of Ellman's reagent. The mixed solution was reacted at room temperature for 15 min after evenly oscillated. The absorption at $412 \mathrm{~nm}$ was measured. The free SH content was calculated according to the following formula:

$$
\mathrm{SH}(\mu \mathrm{mol} / \mathrm{g})=73.53 \times \mathrm{A}_{412} / \mathrm{C}
$$

where $73.53=10^{6} /\left(1.36 \times 10^{4}\right) ; 1.36 \times 10^{4}$ is the molar absorption coefficient of DTNB; $\mathrm{C}$ is the protein concentration $(\mathrm{mg} / \mathrm{mL})$.

\subsection{Matrix-Assisted Laser Desorption/Ionization Time of Flight Mass Spectrometry (MALDI TOF MS) Analysis}

The molecule weight of OVM was determined by MALDI-TOF MS (4800 Plus MALDITOF/TOF Analyzer, AB Science, Framingham, MA, USA) according to the method of Liu et al. [21]. OVM samples were dissolved in distilled water at 1:100. The matrix solution was prepared by the mixing of sinapic acid $(5 \mathrm{mg} / \mathrm{mL})$ in $50 \%$ acetonitrile with $0.1 \%$ TFA. The OVM solution was mixed with the matrix solution at a ratio of $1: 1$. The mixtures $(2.0 \mu \mathrm{L})$ were then dropped onto the MALDI target plate and allowed to dry at room temperature before analysis.

\subsection{High Performance Liquid Chromatography Orbitrap Tandem Mass Spectrometry (HPLC Orbitrap MS/MS) Analysis}

The OVM samples were digested by trypsin at $37^{\circ} \mathrm{C}$ for $24 \mathrm{~h}$. The digested sample solution was separated via a nanoliter flow HPLC system (UltiMate 3000RSLCnano, Thermo Fisher Scientific, Waltham, MA, USA). Solution A was an aqueous solution with $0.1 \%$ formic acid. Solution B was acetonitrile binary solution with $0.1 \%$ formic acid and $84 \%$ acetonitrile. The digested sample solution was injected into a RP-C18 column to remove insoluble or impure substances and then separated by another RP-C18 column at a flow speed of $300 \mu \mathrm{L} / \mathrm{min}$. Gradient elution was then carried out. 
After separation, the eluant was injected into an LTQ-Orbitrap Fusion Velos mass spectrometer (Thermo Fisher Scientific; Waltham, MA, USA) for analysis by tandem mass spectrometry (MS/MS) to identify protein modification forms and sites with a positive ion detection mode. The precursor ions were subjected to high-energy collisional dissociation (HCD) fragmentation to detect fragment ions. Twenty fragment maps (MS/MS ${ }^{2}$ scans) showing the mass-to-charge ratio of the polypeptide and polypeptide fragments were collected at each full scan. Raw files were obtained from the corresponding database using Proteome Discoverer 1.4. Some parameters were set as follows: Enzymes, nonspecified; Missed cleavage, 2; Modification, carbamidomethyl, oxidation, acetylation, phosphorylation, sulfonation, methylation, ubiquitination, nitro.

\subsection{Statistical Analysis}

The values were expressed as means \pm standard deviation from three separate experiments. The analysis was performed using SPSS version 20.0 (SPSS Inc., Chicago, IL, USA). Statistical data were determined based on a two-tailed $t$-test using standard deviations.

\section{Results and Discussion}

\subsection{IgG and IgE Binding Abilities}

The IgG and IgE binding abilities of OVM were estimated through indirect competitive ELISA with sera from rabbit and EWA patients, respectively. As shown in Figure 1A, the IgG binding rate of SS-treated OVM samples significantly decreased with the increase of SS temperature and processing time. The IgG binding rate was markedly influenced by high temperatures and long periods of treatments, with a maximum decline to $28 \%$ when treated at $200{ }^{\circ} \mathrm{C}$ for $10 \mathrm{~min}$. The reduction in the IgG-binding ability of OVM may be due to the structural changes derived from amino acid modification and denaturation [15]. The results implied that SS-created extreme high temperatures of up to $200{ }^{\circ} \mathrm{C}$ might influence the protein structure and destroy IgG allergenicity epitopes.

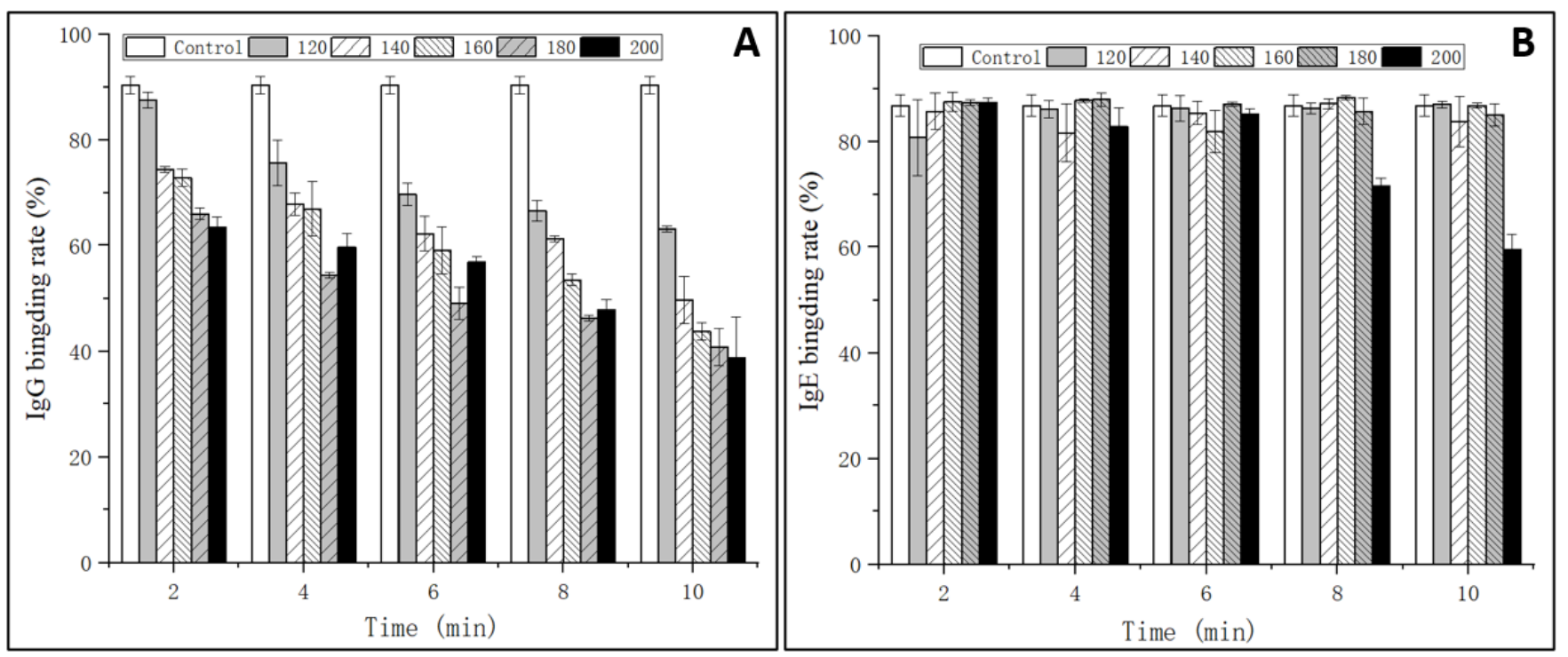

Figure 1. $\operatorname{IgG}(\mathbf{A})$ and $\operatorname{IgE}(\mathbf{B})$ binding rates of OVM treated by SS at different temperatures and times.

However, there were no obvious changes in the IgE binding rate of OVM samples treated by SS, except that at $200{ }^{\circ} \mathrm{C}$ for $8-10 \mathrm{~min}$ (Figure 1B). The results were in accordance with the research of Martos, Lopez-Exposito, Bencharitiwong, Berin, and NowakWegrzyn [22], who reported that heat-treated OVM did not induce the symptoms of anaphylaxis in sensitized mice when administered orally. However, being heated by boiling water for $30 \mathrm{~min}$ did not completely destroy the IgE binding capacity of OVM. Native and SStreated OVM samples at $120-180^{\circ} \mathrm{C}$ for $2-10 \mathrm{~min}$ and $200^{\circ} \mathrm{C}$ for $2-6 \mathrm{~min}$ showed high $\operatorname{IgE}$ 
binding rates, suggesting the persistence of linear epitopes recognized by IgE. This could be caused by the fact that OVM possesses high thermal stability and limited denaturation as the structure is made up of nine disulfide bonds and $25 \%$ carbohydrate [23]. Interestingly, when the heating temperature reached $20{ }^{\circ} \mathrm{C}$ and was maintained for 8-10 min, significant reductions of the IgE binding rate of OVM were observed, declining to $60 \%$ of that of native OVM when treated for $10 \mathrm{~min}$. Therefore, it was confirmed that high heating temperatures could alter the OVM structure more and reduce the content of the IgE epitope in comparison with lower temperatures. In addition, macrophages are also important effector cells that mediate the immune response. The mediators released from basophils may be responsible for the occurrence of Type I allergic reactions. Therefore, the IgE-mediated allergic response was evaluated using a KU812 cell model in the subsequent experiment.

\subsection{Effects of OVM on the Viability and Degranulation of IgE Sensitized KU812 Cells}

To analyze the potential cytotoxic activities of the tested substances, KU812 cells were incubated for $24 \mathrm{~h}$ with increasing concentrations of OVM treated by SS at different temperatures and periods. As shown in Figure 2, compared with the control sample, the absorbance $\left(\mathrm{OD}_{450}\right)$ of cells increased after SS treatment, suggesting that SS heating can promote KU812 cells proliferation. Generally, the absorbance $\left(\mathrm{OD}_{450}\right)$ of cells increased with the increase of OVM concentration and SS processing period. These suggested that a higher OVM concentration and longer SS processing period promoted the KU812 cells proliferation.
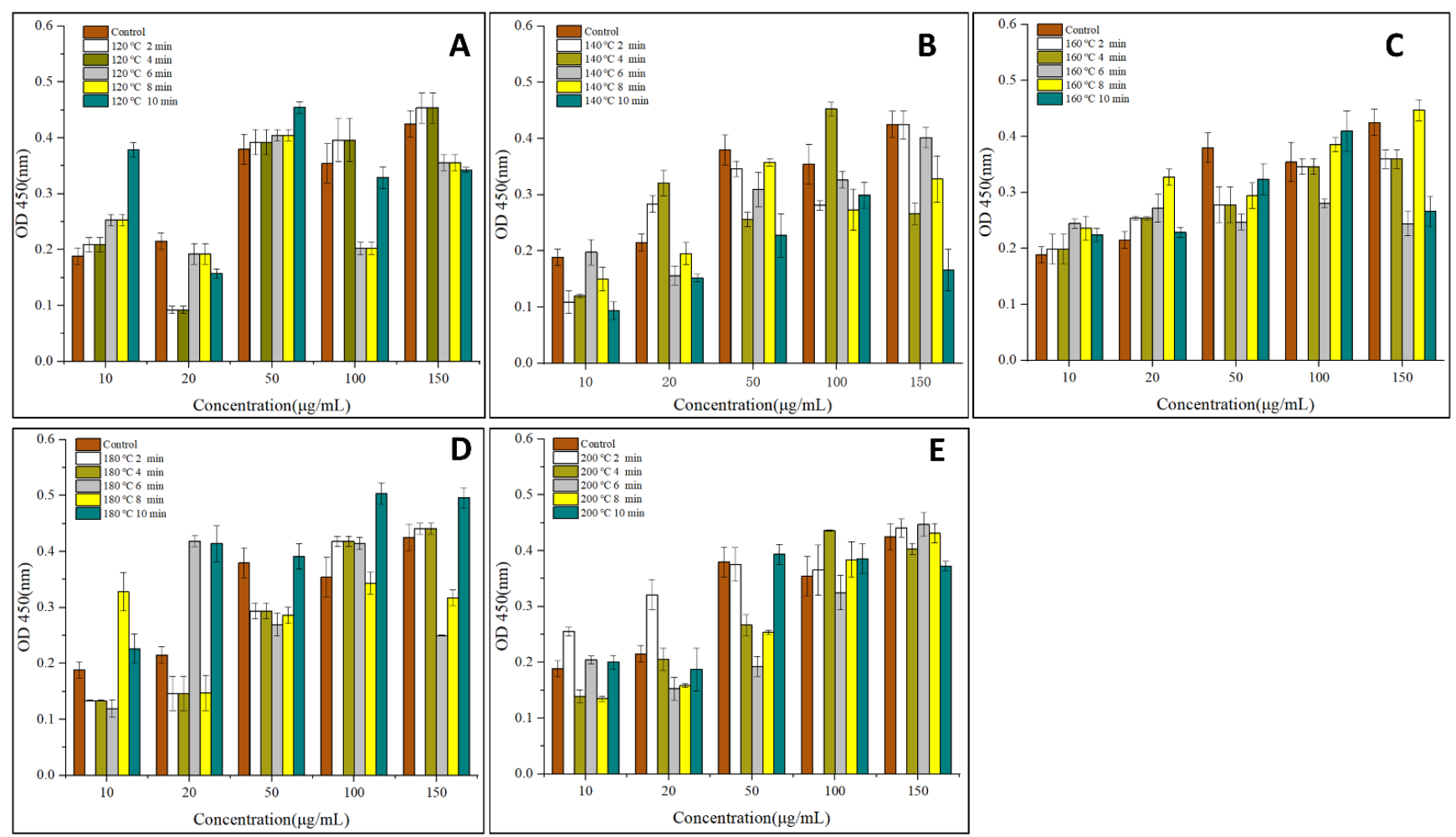

Figure 2. Effects of SS-treated OVM at different temperatures and times on the cell viability (A-E) of the KU812 cells sensitized with sera IgE from patients allergic to egg.

The degranulation rate of basophils and mast cells are key factors that determine the immunoreactivity of allergens. In this work, the effects of SS treatment on the release of $\beta$-hex, TNF- $\gamma$, histamine and IL-6 in KU812 cells are shown in Figure 3. The varying concentrations of 4 types of I cytokines indicated that SS treatment on OVM affected allergic response at the molecular level [24]. 

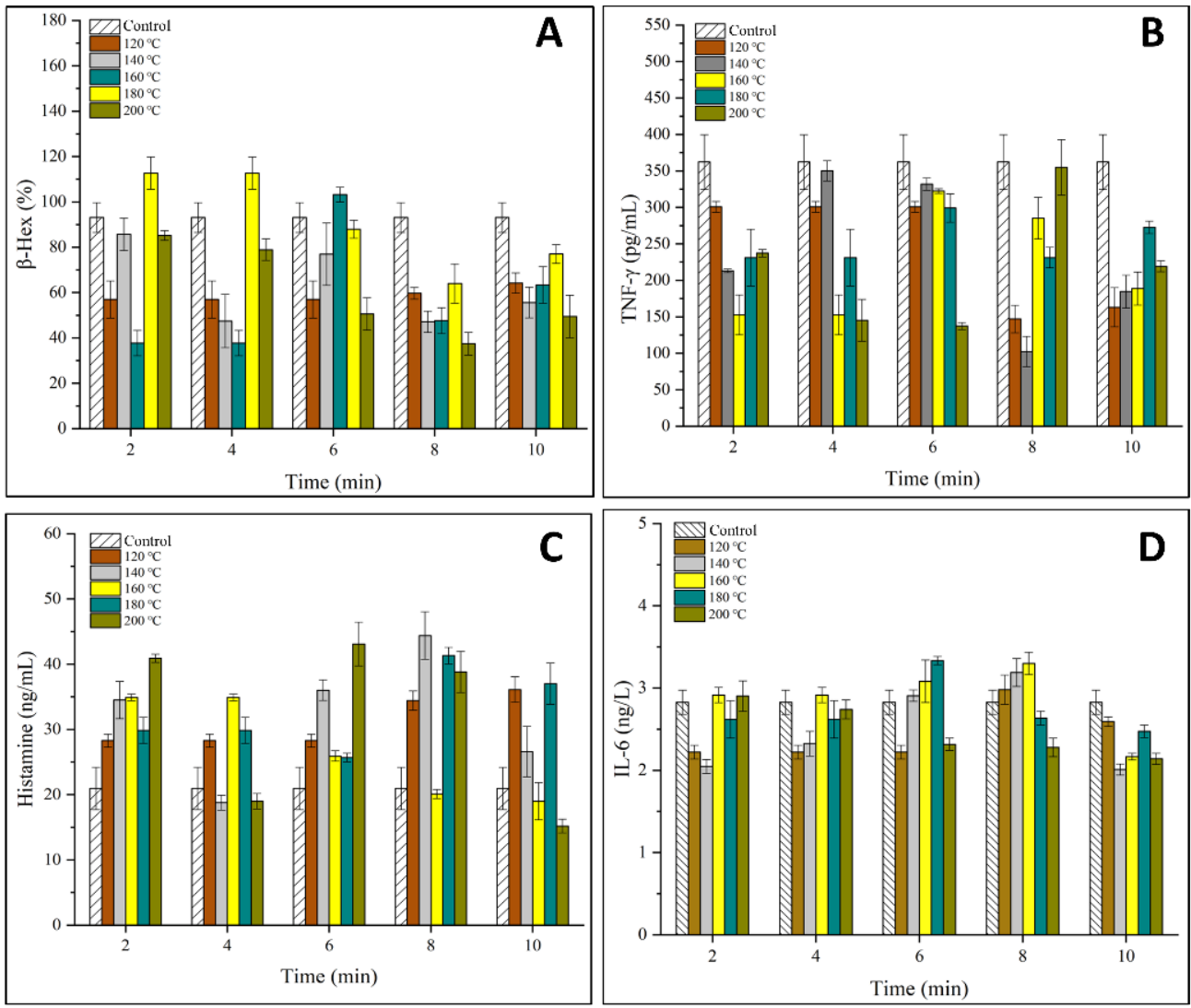

Figure 3. Effects of SS-treated OVM at different temperatures and times on the degranulation of KU812 cells sensitized with sera IgE from patients allergic to egg (A), the release of $\beta$-hex; (B), the release of TNF- $\gamma$; (C), the release of histamine; (D), the release of IL-6).

Figure 3A-C showed that SS treatment inhibited the release of $\beta$-hex and TNF- $\gamma$ while promoting the release of histamine from KU812 cells generally. $\beta$-hex is an indicator of mast cell degranulation in regard to OVM allergenicity. The release of $\beta$-hex was decreased to a minimum of $36 \%$ for SS-treated OVM at $180-200{ }^{\circ} \mathrm{C}$ for $2-10$ min, suggesting that SS treatment at high temperatures could lower the basophil degranulation. This might be due to the cross-linking and aggregation of OVM blocking the interaction between $\operatorname{IgE}$ and allergens by covering parts of the epitopes, leading to less degranulation [7]. TNF- $\gamma$ is an important activity mediator of the immune response or allergenicity response produced or increased in inflammatory disease states [25]. The release of TNF- $\gamma$ decreased by half when OVM was treated at $200{ }^{\circ} \mathrm{C}$ for $10 \mathrm{~min}$, although there exists the experiment error.

Histamine is another key mediator found in KU812 cell granules which is released during antigen-specific IgE binding and plays an important role in the induction of adverse physiological symptoms of an allergic reaction [25]. Interestingly, compared with $\beta$-hex, a higher concentration of histamine was observed with OVM treated by SS at $120-200{ }^{\circ} \mathrm{C}$ for 2-10 min, except for several samples that showed negligible changes. Previous studies have reported similar findings on changes in the $\beta$-hex and histamine release, which suggested that histamine may not be a good indicator of mast cell degranulation in regard to OVM [24].

IL-6 is an important mediator produced in the process of mast cell degranulation. As shown in Figure 3D, no significant increase in the content of IL-6 was detected in KU812 cells, indicating that IL-6 was not stimulated by any antigen from OVM samples.

The above results indicated that the degranulation ability of the basophils was decreased, although there was little change in the IgE binding ability. In conclusion, SS treatment on OVM inhibited the anaphylactic reaction and reduced the release of $\beta$-hex 
and TNF- $\gamma$ in the process of basophilic granulocyte degranulation. The allergenicity of SS-treated OVM decreased in the KU812 cell.

\subsection{Analysis of Oxidation Degree}

Generally, the content of carbonyl is an oxidative indicator of the protein [18]. In this study, the oxidation degree of OVM was analyzed through the determination of the contents of carbonyl and free SH. As shown in Figure 4A, a significant increase of the carbonyl content was observed with the rise of temperature and extension of processing time at $120-160{ }^{\circ} \mathrm{C}$ for $2-6 \mathrm{~min}$ and $200{ }^{\circ} \mathrm{C}$ for $2-4 \mathrm{~min}$. No significant change was observed in OVM treated by SS at $200{ }^{\circ} \mathrm{C}$ for 6-10 min. In an environment of high temperature and high humidity, vaporized water molecules could react with oxygen ions, which will induce the protein backbone of amino acid residue to form peroxyl radicals. Subsequently, carbonyl derivatives were produced via an amidation reaction [26]. However, when the temperature was increased up to $200{ }^{\circ} \mathrm{C}$ and the processing time reached 6-10 $\mathrm{min}$, large amounts of protein aggregation were generated, which influenced the monitoring of the carbony content.
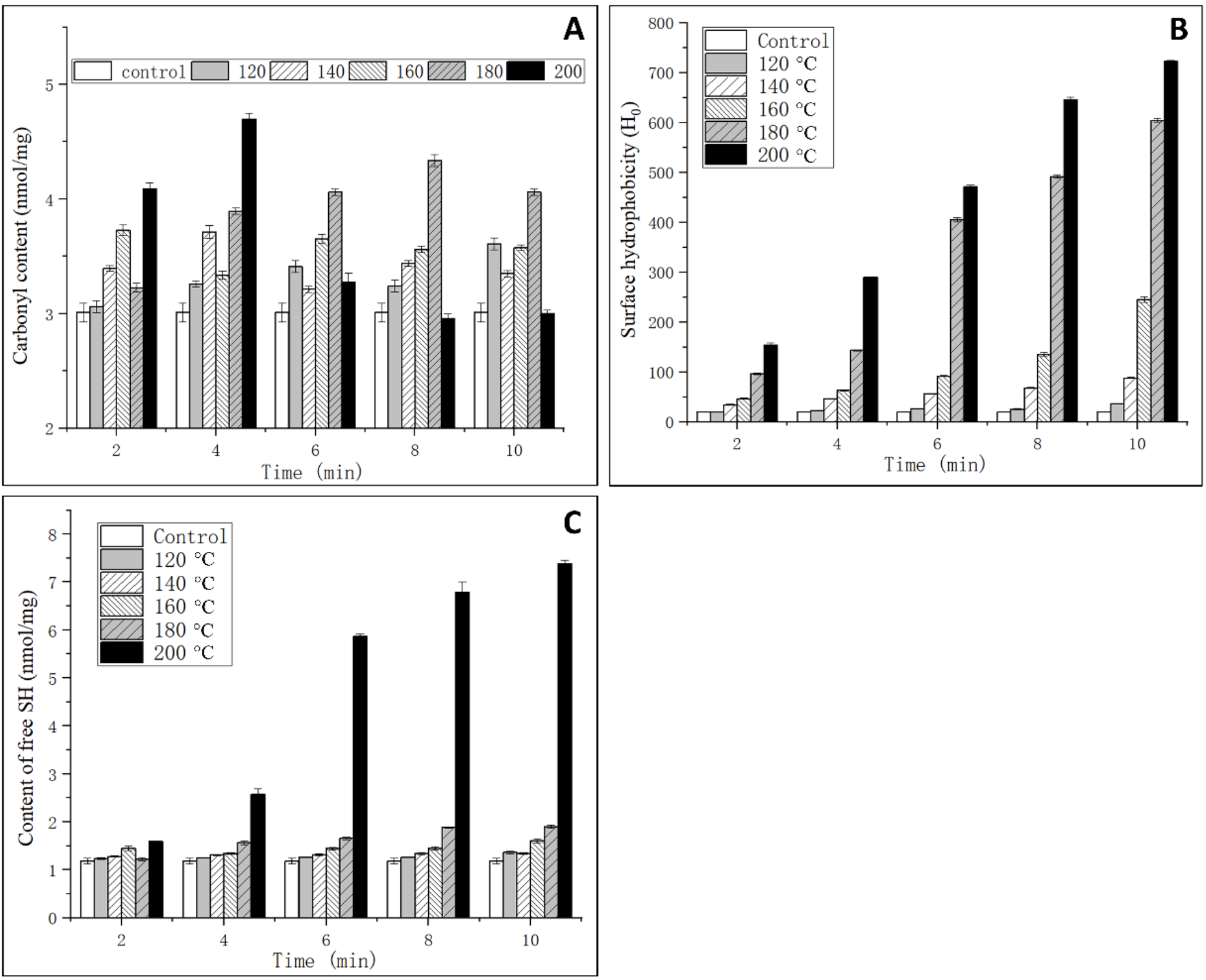

Figure 4. Effects of SS on the carbonyl content (A), surface hydrophobicity (B) and free SH content (C) of OVM. 


\subsection{Analysis of Surface Hydrophobicity}

Surface hydrophobicity is an important index that indicates the binding ability between antibody and antigen. As one type of molecular force involved in immune reactions, surface hydrophobicity plays an important role in assisting in epitope recognition [27]. As shown in Figure 4B, the surface hydrophobicity significantly increased with the increase of temperature and time. The results indicated that SS treatment could induce the unfolding of protein structure, and the internal hydrophobic amino acids were exposed to a nonpolar microenvironment that enhanced the surface hydrophobicity [7]. High temperatures may cause a reduction in steric hindrance against some hydrophobic groups, and ANS is more likely to bind to amino acid residues with cationic groups, such as lysine and arginine. Therefore, it can be concluded that SS treatment could promote the combination of ANS and OVM. It was also concluded that the decrease in IgG binding ability may be related to the increased hydrophobic interactions, while this was not the cause for IgE binding ability.

\subsection{Analysis of Free SH Content}

OVM consists of three structurally independent tandem homologous domains and possesses nine intramolecular disulfide bridges but lacks interdomain disulfide bonds. This is the reason that OVM is resistant to heat denaturation and structural change. The surface hydrophobicity analysis suggested that an unfolding of OVM conformation could occur after SS treatment, which was related to the reduction of disulfide bridges. As shown in Figure $4 \mathrm{C}$, the free SH content significantly increased with the increasing in SS temperature and processing time, and a maximum value was observed when the temperature and processing time reached $200{ }^{\circ} \mathrm{C}$ and $10 \mathrm{~min}$. The native OVM has a free $\mathrm{SH}$ content of $1.1 \mathrm{nmol} / \mathrm{mg}$. After SS treatment at $120-180^{\circ} \mathrm{C}$ for $2-10 \mathrm{~min}$, the free SH content increased to about $1.5 \mathrm{nmol} / \mathrm{mg}$. It is worth noting that at a temperature of $200^{\circ} \mathrm{C}$, the free $\mathrm{SH}$ content drastically increased with the increase in processing time. Generally, high temperature treatment did not cleave the disulfide bridges. However, $200^{\circ} \mathrm{C} \mathrm{SS}$ treatment could catalyze the oxidation of the disulfide bridges to free $\mathrm{SH}$, leading to the unfolding of the protein. Previous studies have reported that reducing the disulfide bonds in OVM can lower allergenicity in vitro [28], which was in accordance with the IgG-binding ability change in this study.

\subsection{Molecular Weight Analysis}

OVM has a molecular mass of $28.0 \mathrm{kDa}$, comprising 186 amino acids and $20-25 \%$ of carbohydrate [29]. Heat treatment could induce the oxidation or aggregation of OVM, increasing the molecular weight as well as forming dimer, trimer or polymer [21,30]. MALDI TOF MS was used to measure the molecular weights of SS-treated OVM samples. The dimer, trimer and tetramer molecule of OVM were observed after SS treatment at $120,140,160$ and $180^{\circ} \mathrm{C}$ for $10 \mathrm{~min}$ (Figure 5), indicating that covalent-binding reactions had occurred. However, there were no obvious changes in dimer among the native and SS-treated OVM samples at $120,140,160,180$ and $200^{\circ} \mathrm{C}$ for $10 \mathrm{~min}$. Interestingly, the single protein molecule and trimer disappeared in the MALDI TOF MS spectrometry of OVM treated at $200{ }^{\circ} \mathrm{C}$ for $10 \mathrm{~min}$. It was presumed that SS treatment at higher temperatures for longer periods might markedly promote the aggregation of proteins, which was not detected by MALDI TOF MS.

\subsection{Modification Sites of OVM}

In order to identify the specific protein sites susceptible to SS treatment and explore the mechanism of the decreasing in OVM allergenicity, it is necessary to find out the precise modification sites of OVM. Previous studies have suggested that the antigenic epitopes in protein sequence mainly originated from hydrophobic amino acids and amino acids containing sulfhydryl groups $[21,31]$. Therefore, trypsin was used to digest native and SStreated OVM at 120, 140 and $200{ }^{\circ} \mathrm{C}$ for $10 \mathrm{~min}$. Table 1 showed the main modified peptides and sites of OVM. It is worth noting that the coverage of the control was $86.67 \%$, much lower 
than SS-treated OVM, reaching 99\%, 99\% and 100\%, respectively. This result indicated that although OVM was a trypsin inhibitor, it could also be hydrolyzed. Only a few structural domains were resistant to trypsin digestion. It also indicated that SS treatment could destruct the native structure of OVM and weaken the anti-digestion property.
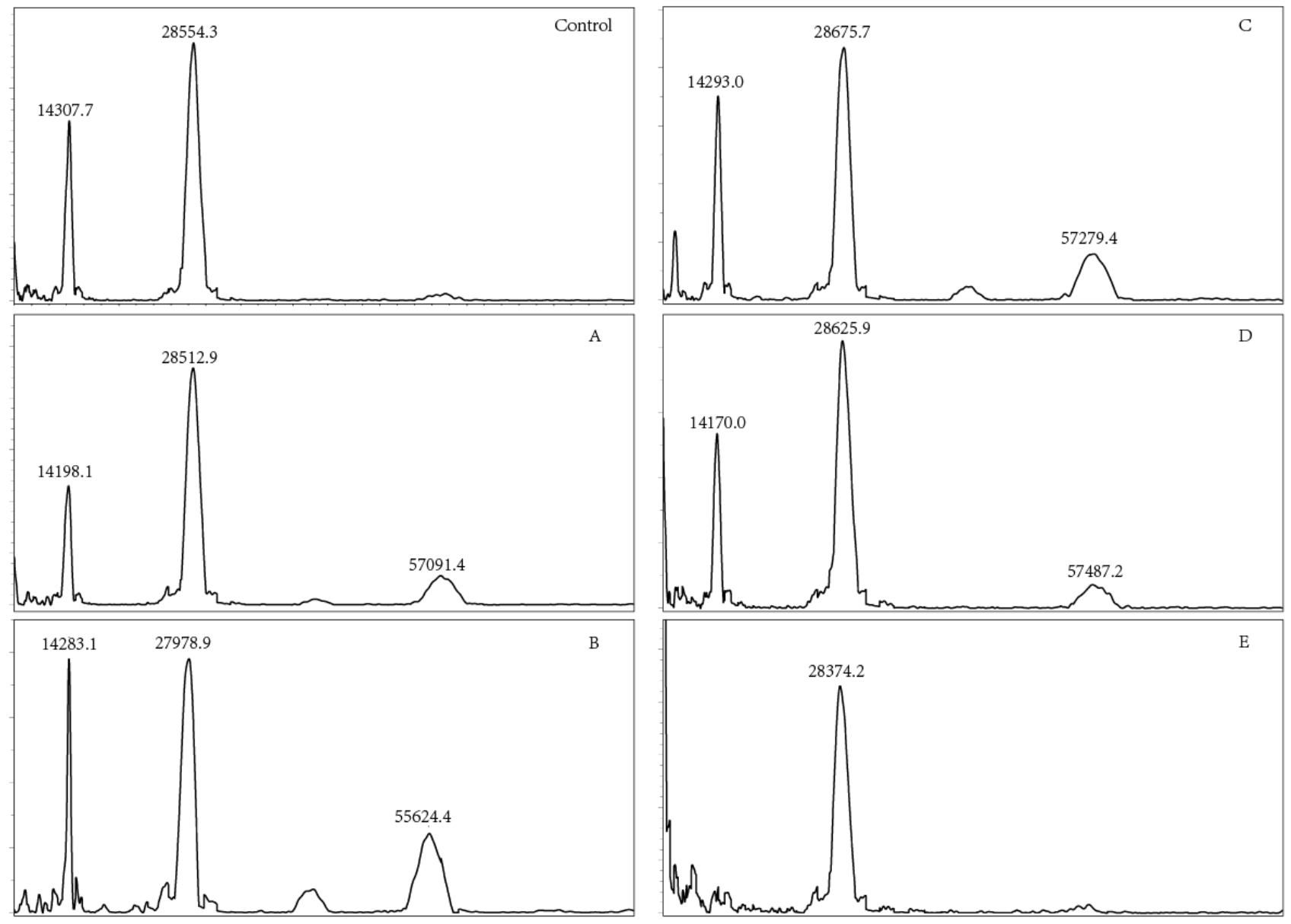

Figure 5. MALDI TOF MS of OVM treated by SS at different temperatures (Control, native OVM; (A-E), OVM treated with SS at 120, 140, 160, 180 and $200^{\circ} \mathrm{C}$, respectively, for $10 \mathrm{~min}$ ).

OVM has a signal sequence of 24 amino acids and a protein sequence of 186 amino acids. Therefore, in this work, the SS-induced changes in 210 amino acids of OVM were explored and mainly concentrated in oxidation, nitro, phospho, carboxymethyl, glygly and sulfo modifications. Oxidative modification is typically associated with lower protein solubility, which can significantly hinder and confound the identification [21,32]. Therefore, only signal sequence M3 produced after treatment at 140 and $200{ }^{\circ} \mathrm{C}$ for $10 \mathrm{~min}$ and protein sequence M84 after treatment at 120,140 and $200{ }^{\circ} \mathrm{C}$ for $10 \mathrm{~min}$ were analyzed. From the results, it can be concluded that SS could catalyze the oxidation of OVM (Table 1). It was also found that nitro modification occurred on some specific amino acids, such as Y73 and Y161. However, the mechanism of the reaction under SS treatment is not yet clear.

Interestingly, it was observed that the phospho modification of OVM occurred after treatment at 120,140 and $200{ }^{\circ} \mathrm{C}$ for $10 \mathrm{~min}$. There were two phospho sites S6 and T38 in native OVM, and three new phospho sites were observed in OVM treated by SS at 120 , 140 and $200{ }^{\circ} \mathrm{C}$ for $10 \mathrm{~min}$. It is worth noting that no phosphate groups participated in this reaction. Therefore, this result indicated that the phospho groups have shifted from phospho sites to non-phospho sites, which was similar to the observation in our previous research [33]. This finding provides a new method to promote the phospho modification of proteins using SS technology. 
Table 1. Modified peptides and sites of the OVM treated by SS.

\begin{tabular}{|c|c|c|c|c|c|}
\hline & & Control & $\begin{array}{l}120^{\circ} \mathrm{C} \text { for } \\
10 \mathrm{~min}\end{array}$ & $140{ }^{\circ} \mathrm{C}$ for $10 \mathrm{~min}$ & $\begin{array}{l}200^{\circ} \mathrm{C} \text { for } \\
10 \mathrm{~min}\end{array}$ \\
\hline \multicolumn{2}{|c|}{ Coverage } & $86.67 \%$ & $99 \%$ & $99 \%$ & $100 \%$ \\
\hline \multicolumn{6}{|c|}{ Signal sequence 1-24 } \\
\hline \multirow{4}{*}{ Modification } & Oxidation & & & M3 & M3 \\
\hline & Nitro & M3 & M3 & & \\
\hline & Phosphor & S11 & S11 & S11 & S11 \\
\hline & Carboxymethyl & C15 & C15 & C15 & C15 \\
\hline \multicolumn{6}{|c|}{ Protein signal sequence 1-186 } \\
\hline \multirow{6}{*}{ Modification } & Oxidation & & M84 & M84 & M84 \\
\hline & Nitro & Y102, Y141 & Y102, Y141 & Y102, Y141 & $\begin{array}{l}\text { Y73, Y102, } \\
\text { Y141, Y161 }\end{array}$ \\
\hline & Phosphor & S6, T38 & S6, T12, T52, T160 & S6, T12, T52, T160 & S6, T12, T52, T160 \\
\hline & Carboxymethyl & $\begin{array}{c}\text { C5, C22, C30, C41, } \\
\text { C44, C } 87, \text { C95, } \\
\text { C106, C109, C138, } \\
\text { C146, C154, } \\
\text { C165, C168 }\end{array}$ & $\begin{array}{c}\text { C5, C22, C30, C41, } \\
\text { C44, C70, C87, C95, } \\
\text { C106, C109, C138, } \\
\text { C146, C154, } \\
\text { C165, C168 }\end{array}$ & $\begin{array}{c}\text { C5, C22, C30, C41, } \\
\text { C44, C70, C87, C95, } \\
\text { C106, C109, C138, } \\
\text { C146, C154, } \\
\text { C165, C168 }\end{array}$ & $\begin{array}{c}\text { C5, C22, C30, C41, } \\
\text { C44, C70, C87, C95, } \\
\text { C106, C109, C138, } \\
\text { C146, C154, } \\
\text { C165, C168 }\end{array}$ \\
\hline & Glygly & $\begin{array}{c}\text { K14, K56, T32, S55, } \\
\text { K112, K121 }\end{array}$ & $\begin{array}{c}\text { K14, K56, T32, S55, } \\
\text { K112, K121, S71, } \\
\text { S72, S78 }\end{array}$ & $\begin{array}{c}\text { K14, K56, T32, S55, } \\
\text { K112, K121, S71, } \\
\text { S72, S78 }\end{array}$ & $\begin{array}{c}\text { K14, K56, T32, S55, } \\
\text { K112, K121, S71, } \\
\text { S72, S78 }\end{array}$ \\
\hline & Sulfo & T36 & T36 & $\mathrm{T} 36$ & $\begin{array}{c}\text { T36, S6, S47, } \\
\text { S156, S174 }\end{array}$ \\
\hline
\end{tabular}

There was also an important finding in regard to glygly modification, which plays an important role in life activities. Similarly, three new glygly sites S71, S72 and S78 were observed in OVM treated at 120,140 and $200{ }^{\circ} \mathrm{C}$ for $10 \mathrm{~min}$, without the participation of the glygly group. The internal transfer might be the reason for the generation of new glygly modification sites in the OVM molecule. Finally, the sulfo modification sites among native and SS-treated OVM at 120,140 and $200^{\circ} \mathrm{C}$ for $10 \mathrm{~min}$ were also compared. There were four new sulfo sites (S6, S47, S156 and S174) observed in OVM treated at $200{ }^{\circ} \mathrm{C}$ for $10 \mathrm{~min}$. The sulfuric groups may be originated from cysteine or other sulfo sites. Interestingly, serine could be readily modified with the acquisition of functional groups from other modification sites during SS treatment.

OVM molecule is organized into three well-separated domains which play an important role in inducing allergic reactions. It is important to explore the relationship between the sensitive modification sites and the three-dimensional (3D) structure of SS-treated OVM. The modification sites of OVM treated at $120^{\circ} \mathrm{C}, 140{ }^{\circ} \mathrm{C}$ and $200{ }^{\circ} \mathrm{C}$ for $10 \mathrm{~min}$ are shown in Figure 6. OVM treated at $120^{\circ} \mathrm{C}$ for 10 min exhibited similar modification sites with that treated at $140{ }^{\circ} \mathrm{C}$ for $10 \mathrm{~min}$, and the $3 \mathrm{D}$ diagrams of three domains are presented in Figure 6A. The content of modification sites was higher in OVM treated at $200{ }^{\circ} \mathrm{C}$ for $10 \mathrm{~min}$ (Figure 6B). Interestingly, the modification sites including T52, T12, S71, S72, S78, M84 and T160 were all found in the $\beta$-sheet structure of SS-treated OVM at $120^{\circ} \mathrm{C}$ and $140{ }^{\circ} \mathrm{C}$ for $10 \mathrm{~min}$. However, for the SS-treated OVM at $200{ }^{\circ} \mathrm{C}$ for $10 \mathrm{~min}$, S47 was found in the $\alpha$-helix structure, and S156 was found in the structure. From these results, it suggested that the low temperature of SS always modifies the amino acids located on $\beta$-sheet which were relatively fragile. Meanwhile, the higher temperature treatment of $200^{\circ} \mathrm{C}$ could also attack the amino acids located on $\alpha$-helices and $\beta$-turn of OVM and promote the modification reaction. 
A

Domain 1

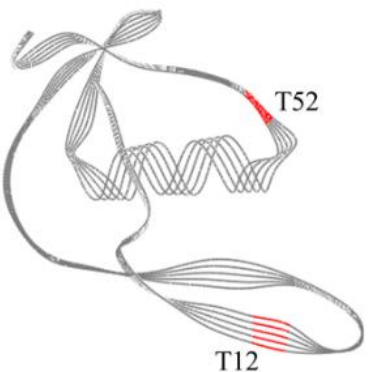

B

Domain 1

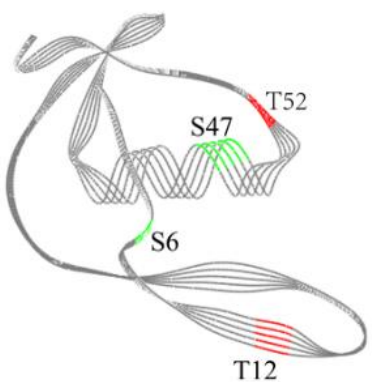

Domain 2

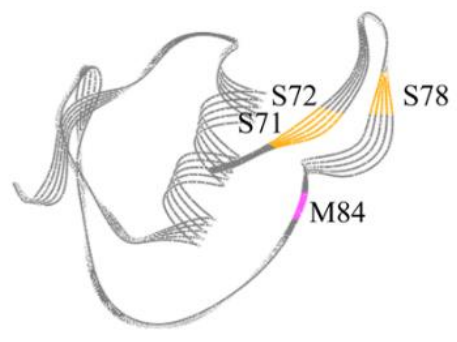

Domain 2

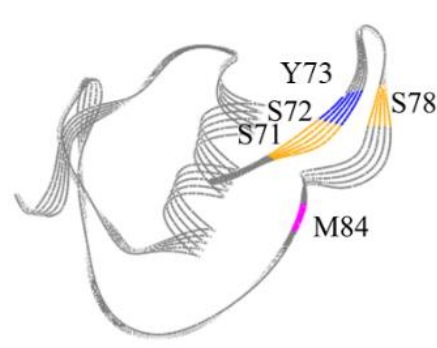

Domain 3

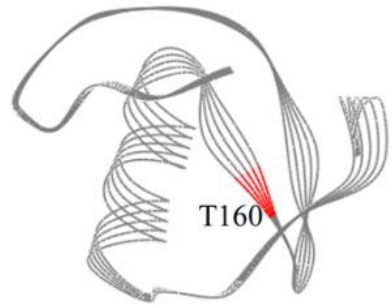

Domain 3

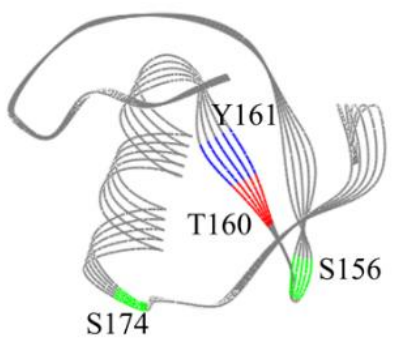

Figure 6. Modification sites in $3 \mathrm{D}$ diagrams of the three domains of SS-treated OVM. (A), $120^{\circ} \mathrm{C}$ for $10 \mathrm{~min}$ and $140{ }^{\circ} \mathrm{C}$ for $10 \mathrm{~min}$; (B), $200{ }^{\circ} \mathrm{C}$ for $10 \mathrm{~min}$; purple, oxidation modification; blue, nitro modification; red, phosphorylation; orange, glygly modification; green, sulfo modification.

SS treatment, particularly at high temperatures and long processing times, could induce the OVM aggregation, increase surface hydrophobicity, modify the functional groups and amino acids in OVM. These phenomena disrupted and buried some allergen epitopes and made it difficult for the combination of antibodies and antigens [14,15]. Therefore, the allergenicity of OVM was decreased and the anaphylactic reaction in the KU812 cell was inhibited.

\section{Conclusions}

To our knowledge, this is the first study investigating the allergenicity and structure changes of OVM under SS treatment. A decrease in the IgG-binding ability was observed for SS-treated OVM with no significant changes in the IgE binding ability. SS treatment reduced the release of $\beta$-hex and TNF- $\gamma$, promoted the release of histamine, while having no significant effect on IL-6 release in KU812 cells. An obvious increase in the oxidation degree, free SH content and surface hydrophobicity were observed. Trimer and tetramer aggregations generated after SS treatment. In addition, there were obvious changes in the primary structure. Furthermore, some amino acids could be readily modified by obtaining functional groups from other modification sites during SS treatment. It can be inferred that SS-induced OVM aggregation, functional groups and amino acids modifications as well as protein structure alteration led to the reduction in allergenicity and increase in digestibility.

Author Contributions: P.-W.W.: Writing—original draft, Methodology, Validation, Formal analysis. Z.-C.T.: Funding acquisition, Validation, Resources. Y.-M.H.: Formal analysis, Supervision. H.W.: Supervision, Software, Visualization. All authors have read and agreed to the published version of the manuscript.

Funding: This research was funded by National Natural Science Foundation of China (No. 32101946) and Jiangxi Provincial Natural Science Foundation (20212BAB215037). 
Data Availability Statement: The data presented in this study are available on request from the corresponding author. The data are not publicly available due to privacy or ethical restrictions.

Conflicts of Interest: The authors declare no competing financial interest.

Abbreviations
SS
IgE
IgG
KU812 cells
$\beta$-hex
IL-6
DTT
ANS
SH
ELISA
MALDI TOF MS
HPLC Orbitrap MS/MS
DNPH

\author{
superheated steam \\ immunoglobulin E \\ immunoglobulin G \\ human peripheral blood basophilic leukemia cells \\ $\beta$-hexosaminidase \\ interleukin-6 \\ dithiothreitol \\ 8-aniline-1-naphthalene sulfonic acid \\ sulfhydryl \\ enzyme-linked immunosorbent assay
}

Matrix-assisted laser desorption/ionization time of flight mass spectrometry

high performance liquid chromatography Orbitrap tandem mass spectrometry

2,4-dinitrophenylhydrazine

\section{References}

1. He, W.; Xu, H.; Lu, Y.; Zhang, T.; Li, S.; Lin, X.; Xu, B.; Wu, X. Function, digestibility and allergenicity assessment of ovalbuminEGCG conjugates. J. Funct. Foods 2019, 61, 103490. [CrossRef]

2. Pablos-Tanarro, A.; Lozano-Ojalvo, D.; Molina, E.; López-Fandiño, R. Assessment of the allergenic potential of the main egg white proteins in BALB/c mice. J. Agric. Food Chem. 2018, 11, 2970-2976. [CrossRef] [PubMed]

3. Mine, Y.; Zhang, J.W. Comparative studies on antigenicity and allergenicity of native and denatured egg white proteins. J. Agric. Food Chem. 2002, 50, 2679-2683. [CrossRef] [PubMed]

4. Azdad, O.; Mejrhit, N.; Aarab, L. Reduction of the allergenicity of cow's milk $\alpha$-lactalbumin under heat-treatment and enzymatic hydrolysis in Moroccan population. Eur. Ann. Allergy Clin. Immunol. 2018, 50, 177-183. [CrossRef]

5. Li, H.J.; Zhu, K.X.; Zhou, H.M.; Peng, W.; Guo, X.N. Comparative study of four physical approaches about allergenicity of soybean protein isolate for infant formula. Food Agric. Immunol. 2016, 27, 1-20. [CrossRef]

6. Fredericq, E.; Deutsch, H.F. Studies on ovomucoid. J. Biol. Chem. 1949, 181, 499-510. [CrossRef]

7. Hu, Y.; Wang, L.; Li, Z. Modification of protein structure and dough rheological properties of wheat flour through superheated steam treatment. J. Cereal Sci. 2017, 76, 222-228. [CrossRef]

8. Hu, Y.; Wang, L.; Hu, X.; Li, Z. Microbial decontamination of wheat grain with superheated steam. Food Control 2016, 62, 264-269. [CrossRef]

9. Sehrawat, R.; Nema, P.K.; Kaur, B.P. Effect of superheated steam drying on properties of foodstuffs and kinetic modeling. Innov. Food Sci. Emerg. 2016, 34, 285-301. [CrossRef]

10. Zhang, N.C.; Gao, Y.Q.; Tong, L.T.; Li, Z.G. Superheated steam processing improved the qualities of oats flour and noodles. J. Cereal Sci. 2018, 83, 96-100. [CrossRef]

11. Ceccanti, C.; Pellegrini, E.; Guidi, L. Effect of superheated steam and conventional steam roasting on nutraceutical quality of several vegetables. LWT-Food Sci. Technol. 2021, 149, 112014. [CrossRef]

12. Hu, X.; Guo, B.; Liu, C.; Yan, X.; Chen, J.; Luo, S.; Liu, Y.; Wang, H.; Yang, R.; Zhong, Y.; et al. Modification of potato starch by using superheated steam. Carbohyd. Polym. 2018, 198, 375-384. [CrossRef] [PubMed]

13. Wu, J.; Chen, J.; Liu, W.; Liu, C.; Zhong, Y.; Luo, D.; Li, Z.; Huang, Z. Selective peroxidase inactivation of lightly milled rice by superheated steam. J. Cereal Sci. 2014, 60, 623-630. [CrossRef]

14. Wang, X.M.; Tu, Z.C.; Ye, Y.H.; Liu, G.X.; Wang, H.; Hu, Y.M. Mechanism on the allergenicity changes of $\alpha$-lactalbumin treated by sonication-assisted glycation during in vitro gastroduodenal digestion. J. Agric. Food Chem. 2021, 69, 6850-6859. [CrossRef]

15. Wang, X.M.; Ye, Y.H.; Tu, Z.C.; Hu, Y.M.; Wang, H.; Huang, T. Mechanism of the reduced IgG/IgE binding abilities of glycated $\beta$-lactoglobulin and its digests through high-resolution mass spectrometry. J. Agric. Food Chem. 2021, 69, 3741-3750. [CrossRef] [PubMed]

16. Kuehn, H.S.; Radinger, M.; Brown, J.M.; Ali, K.; Vanhaesebroeck, B.; Beaven, M.A.; Metcalfe, D.D.; Gilfillan, A.M. Btk-dependent Rac activation and actin rearrangement following FceRI aggregation promotes enhanced chemotactic responses of mast cells. J. Cell Sci. 2010, 123 Pt 15, 2576-2585. [CrossRef]

17. Lv, L.T.; Lin, H.; Li, Z.X.; Nayak, B.; Ahmed, I.; Tian, S.L.; Chen, G.Z.; Lin, H.; Zhao, J.X. Structural changes of 2,2'-Azobis (2-amidinopropane) dihydrochloride (AAPH) treated shrimp tropomyosin decrease allergenicity. Food Chem. 2018, $274,547-557$. [CrossRef] 
18. Zhang, J.J.; Tu, Z.C.; Wang, H.; Hu, Y.M.; Du, P.C.; Yang, Y.P. Mechanism of the effect of 2, 2'-azobis (2-amidinopropane) dihydrochloride simulated lipid oxidation on the IgG/IgE binding ability of ovalbumin. Food Chem. 2020, 327, 127037. [CrossRef]

19. Xi, C.; Kang, N.; Zhao, C.; Liu, Y.; Sun, Z.; Zhang, T. Effects of pH and different sugars on the structures and emulsification properties of whey protein isolate-sugar conjugates. Food Biosci. 2020, 33, 100507. [CrossRef]

20. Ellman, G.L. Tissues sulfhydryl groups. Arch. Biochem. Biophys. 1959, 82, 70-77. [CrossRef]

21. Liu, G.X.; Tu, Z.C.; Yang, W.H.; Wang, H.; Zhang, L.; Ma, D.; Huang, T.; Liu, J.; Li, X. Investigation into allergenicity reduction and glycation sites of glycated $\beta$-lactoglobulin with ultrasound pretreatment by high-resolution mass spectrometry. Food Chem. 2018, 252, 99-107. [CrossRef]

22. Martos, G.; Lopez-Exposito, I.; Bencharitiwong, R.; Berin, M.C.; Nowak-Wegrzyn, A. Mechanisms underlying differential food allergy response to heated egg. J. Allergy Clin. Immun. 2011, 127, 990-997. [CrossRef]

23. Djurtoft, R.; Pedersen, H.S.; Aabin, B.; Barkholt, V. Studies of food allergens: Soybean and egg proteins. Adv. Exp. Med. Biol. 1991, 289, 281-293. [PubMed]

24. Rupa, P.; Schnarr, L.; Mine, Y. Effect of heat denaturation of egg white proteins ovalbumin and ovomucoid on CD4+ T cell cytokine production and human mast cell histamine production. J. Funct. Foods. 2015, 18, 28-34. [CrossRef]

25. Cianferoni, A.; Muraro, A. Food-induced anaphylaxis. Immunol. Allergy Clin. N. Am. 2012, 32, 165-195. [CrossRef]

26. Zhou, F.B.; Zhao, M.M.; Zhao, H.F.; Sun, W.F.; Cui, C. Effects of oxidative modification on gel properties of isolated porcine myofibrillar protein by peroxyl radicals. Meat Sci. 2014, 96, 1432-1439. [CrossRef]

27. Chandrapala, J.; Zisu, B.; Palmer, M.; Kentish, S.; Ashokkumar, M. Effects of ultrasound on the thermal and structural characteristics of proteins in reconstituted whey protein concentrate. Ultrason Sonochem. 2011, 18, 951-957. [CrossRef] [PubMed]

28. Kovacs-Nolan, J.; Zhang, J.W.; Hayakawa, S.; Mine, Y. Immunochemical and structural analysis of pepsin-digested egg white ovomucoid. J. Agric. Food Chem. 2000, 48, 6261-6266. [CrossRef]

29. Mine, Y.; Yang, M. Recent advances in the understanding of egg allergens: Basic, industrial, and clinical perspectives. J. Agric. Food Chem. 2008, 56, 4874-4900. [CrossRef]

30. Ma, Y.; Zhang, H.; Xu, D.; Jin, Y.; Xu, X. Wheat flour superheated steam treatment induced changes in molecular rearrangement and polymerization behavior of gluten. Food Hydrocolloid. 2021, 118, 106769. [CrossRef]

31. Yang, Y.P.; Liu, G.X.; Wang, H. Investigation of the mechanism of conformational alteration in ovalbumin as induced by glycation with different monoses through conventional spectrometry and liquid chromatography high-resolution mass spectrometry. J. Agric. Food Chem. 2019, 67, 3096-3105. [CrossRef] [PubMed]

32. Dyer, J.M.; Clerens, S.; Thomas, A.; Callaghan, C.; Deb-Choudhury, S.; Haines, S. Photo-oxidation of whey proteins: Molecular markers of modification. Int. Dairy J. 2017, 66, 56-60. [CrossRef]

33. Wang, H.; Zong, B.Z.; Liu, G.X.; Zhang, L.; Chen, Y. Identification and quantification of the phosphorylated ovalbumin by high resolution mass spectrometry under dry-heating treatment. Food Chem. 2016, 210, 141-147. [CrossRef] [PubMed] 